\title{
Use of passive microwave remote sensing to monitor soil moisture
}

\author{
Jean-Pierre Wigneron ${ }^{\mathrm{a}^{*}}$, Thomas Schmugge ${ }^{\mathrm{b}}$, André Chanzy ${ }^{\mathrm{c}}$, \\ Jean-Claude Calvet ${ }^{\mathrm{d}}$, Yann Kerr ${ }^{\mathrm{e}}$ \\ $\mathrm{a}^{*}$ Inra, Bioclimatologie, Agroparc, 84914 Avignon cedex 9, France \\ bUSDA/ARS, Hydrology Lab, BARC-West, Beltsville MD, USA \\ 'Inra, Sc du sol, Agroparc, 84914 Avignon cedex 9, France \\ 'Météo France / CNRM, 42, av Coriolis, 31057 Toulouse cedex 1, France

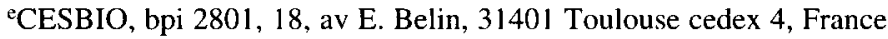

(Received 11 December 1997; accepted 21 January 1998)

\begin{abstract}
Surface soil moisture is a key variable to describe the water and energy exchanges at the land surface/atmosphere interface. However, soil moisture is highly variable both spatially and temporally. Passive microwave remotely sensed data have great potential for providing estimates of soil moisture with good temporal repetition (on a daily basis) and at regional scale $(\sim 10 \mathrm{~km})$. This paper reviews the various methods for remote sensing of soil moisture from microwave radiometric systems. Potential applications from both airborne and spatial observations are discussed in the fields of agronomy, hydrology and meteorology. Emphasis in this paper is given to relatively new aspects of microwave techniques and of temporal soil moisture information analysis. In particular, the aperture synthesis technique allows us now to a address the soil moisture information needs on a global basis, from space instruments. ( $\odot$ Inra/Elsevier, Paris.)
\end{abstract}

remote sensing / microwave radiometry / soil moisture / vegetation water status / evapotranspiration

Résumé - Utilisation des mesures de télédétection micro-onde passive pour le suivi de l'humidité du sol. Synthèse. L'humidité de surface du sol est une variable clé pour décrire les échanges d'eau et d'énergie à l'interface surface terrestre-atmosphère. Cependant, l'humidité du sol varie fortement dans le temps et l'espace. Les données de télédétection micro-onde passive ont un fort potentiel pour fournir des estimations de l'humidité du sol avec une bonne résolution temporelle (sur une base journalière) et à une échelle régionale $(-10 \mathrm{~km})$. Cet article fait une revue des différentes méthodes de suivi de l'humidité sol à partir de radiomètres micro-ondes. Les applications potentielles s'appuyant sur des mesures aéroportées et spatiales sont analysées dans les domaines de l'agronomie, la météorologie et l'hydrologie. Nous insistons sur des aspects relativement nouveaux de la technique de mesure micro-onde et de l'analyse de séries temporelles d'humidité du sol. En particulier, la technique de synthèse d'ouverture permet maintenant de répondre aux besoins en information sur l'humidité de surface à l'échelle de la biosphère, à partir d'instruments spatiaux. (C Inra/Elsevier, Paris.)

télédétection / radiométrie micro-onde / humidité du sol / état hydrique de la végétation / évapotranspiration

Communicated by Gérard Guyot (Avignon)

* Correspondence and reprints

E-mail: wigneron@avignon.inra.fr 


\section{INTRODUCTION}

Previous research has shown that microwave remote sensing sensors can be used to estimate surface soil moisture. These estimates can provide a better knowledge of the temporal and spatial variations in soil moisture, which is important in the fields of hydrology, agriculture and meteorology. Surface soil moisture (hereafter referred to as $\mathrm{wg}$ and corresponding roughly to the $0-5 \mathrm{~cm}$ top soil layer) is a key variable in the water and energy exchanges at the land surface/atmosphere interface. This variable is of crucial importance for several aspects.

In hydrology and meteorology, the water content of the surface soil layer is a pertinent descriptor of the water exchanges between the surface and the atmosphere. For instance Chanzy and Bruckler [7] showed that $\mathrm{wg}$ is a key variable to estimate the ratio between evaporation and potential evaporation over bare soils. Also, soil moisture is an important variable to estimate the distribution of precipitation between storm runoff and storage and to compute several key variables of the land surface energy and water budget (albedo, hydraulic conductivity, etc.).

In agronomy, surface soil moisture is important for the development of crops during the early phases of the growth (germination, development of the root system, etc.) and also for cultural practices (trafficability in the fields). According to Brisson and Perrier [2], the interest in monitoring the soil surface water status for crop simulation models is threefold: 1) it allows a better estimation of transpiration processes (the maximum transpiration depends on the soil moisture status through an effect of microlocal advection: higher temperatures and lower values of air moisture over dry soils increase the climatic demand at plant level); 2) it makes it possible to estimate the water status of plants at the beginning of the crop cycle; 3 ) it allows modelling of the mulch (soil dry surface layer) which is of interest in drastic dry conditions during the emergence stage (in this case competition between rooting and mulch deeping may be observed).
At this point of the Introduction it is important to distinguish the surface soil moisture ( $\sim$ water content of the $0-5 \mathrm{~cm}$ top soil layer) which can be estimated using remote sensing (R-S) measurements, from the soil water content at depth. Actually, the microwave R-S techniques cannot provide direct estimates of the water availability for plants which is in relation to the soil moisture in the root zone (hereafter referred to as w2) and root depth. However, as discussed in this review, modelling of the heat and mass flow within soil can be used to derive information about the soil water content at depth from temporal surface soil moisture information. Water availability for plants is a key variable to evaluate vegetation transpiration which is a key term in the energy and water budgets over vegetation covers.

In summary, the estimation of actual evapotranspiration ET for applications in agriculture, meteorology and hydrology, requires repetitive estimates of surface soil moisture (to compute direct evaporation from the soil) and to derive information about the soil water content in the root zone (to compute water flows due to vegetation transpiration). The estimation of ET over land surfaces is an important issue for meteorological modelling, since it is a basic term of the land surface forcing in mesocale atmospheric circulations [38].

Soil moisture is highly variable both spatially and temporally in the natural environment, as the results of the inhomogeneity of soil properties, topography, land cover and the nonuniformity of rainfall and evapotranspiration. Remotely sensed data, which can provide frequent and spatially comprehensive estimates of the land surface characteristics, arouse a large interest. The use of microwave remote sensing techniques to estimate surface soil moisture has been the object of much research over the past two decades [46]. In the microwave region of the electromagnetic spectrum, soil reflectivity is mainly driven by the soil moisture content, owing to the large contrast between the dielectric properties of liquid water and of dry soil. Based on this property, active (radar systems) and passive (radiometric systems) microwave observations.can provide estimates of soil moisture from space-borne platforms. The data acquired from the microwave sensors at 
low-frequency bands ( $\mathrm{f}<15 \mathrm{GHz}$ ) are very attractive since they are insensitive to solar effects (as a source of illumination) and weakly sensitive to atmospheric effects. Therefore, regular observations can be made (the microwave sensor can observe the land surface characteristics through clouds) and it is usually not necessary to correct for atmospheric gaseous absorption and emission effects.

The two types of microwave sensors (active and passive) have distinct advantages, which make them better suited for different fields of activities.

Active sensors offer possibilities of high spatial resolution: about $10 \mathrm{~m}$ for the synthetic aperture radar (SAR) installed aboard the satellites ERS (Europe) and Radarsat (Canada). The measurement is very sensitive to the geometry of the surface (in terms of soil roughness, vegetation structure, row effects due to crop rows or tillage, look angle, etc.). Usually, in relation to high spatial sampling, the temporal repetition of the SAR measurement is very low and usually exceeds 1 month. Over vegetation covers, the active data have shown very good capabilities for vegetation type discrimination and forest biomass retrieval.

Passive sensors are limited to a rather coarse resolution of about $10-20 \mathrm{~km}$ at L-band $(1.4 \mathrm{GHz})$, which is an optimal frequency band for soil moisture monitoring. However, this spatial resolution is in agreement with the grid scales on the order of $10-100 \mathrm{~km}$ of mesoscale meteorological and climate models. Also, in comparison with radars, passive systems have a greater sensitivity to soil moisture and are less sensitive to surface geometry. Therefore, simplified algorithms can be used to account for soil surface roughness and vegetation structure. Thus, the passive data can provide global monitoring of the earth with a daily temporal sampling which is particularly well-suited for mesoscale meteorological applications.

This paper reviews the current understanding of passive microwave remote sensing of soil moisture. Algorithms and methods developed to retrieve surface variables (surface soil moisture, surface temperature and biomass) from microwave data are presented. The discussion includes the require- ments for sensor design, current capabilities for soil moisture monitoring and recent advances in the analysis of temporal soil moisture information.

\section{MODELLING OF THE MICROWAVE EMISSION}

The passive microwave radiometer measures the natural thermal emission of the land surface in the microwave region (frequency ranges roughly from 0.3 to $300 \mathrm{GHz}$ ). The measurement of the spectral brightness $\mathrm{B}^{\mathrm{f}}\left(\mathrm{Wm}^{-2} \mathrm{sr}^{-1} \mathrm{~Hz}^{-1}\right)$ of the surface is expressed in terms of brightness temperature $\mathrm{Tb}_{\mathrm{P}}$ $(\mathrm{K})$, where $\mathrm{B}_{\mathrm{f}}=2 \mathrm{kT} \mathrm{Tb}_{\mathrm{p}} / \lambda^{2}$ from the RayleighJeans approximation to Planck's equation $(\mathrm{k}=$ Boltzmann's constant, $\lambda=$ wavelength $(\mathrm{m})$ ). The subscript $p$ denotes the polarization of the measured radiation $(\mathrm{p}=\mathrm{v}$ or $\mathrm{p}=\mathrm{h}$, for vertical or horizontal polarization, respectively). The surface emissivity $e_{P}$ is related to $T b_{P}$ using a simple equation: $e_{P}=T_{P} / T_{\text {eff }}$, where $T_{\text {eff }}$ is an effective microwave surface temperature. The value of $\mathrm{T}_{\text {eff }}$ is close to that derived from thermal infrared measurements.

In the following sections, the basic principles of the modelling of $\mathrm{Tb}_{\mathrm{P}}$ are presented. The remote sensing models can be used to describe and quantify the microwave measurement sensitivity to the land surface variables. Also, using model inversion procedures, retrieval of the surface variables of interest can be carried out from the remote sensing measurements.

\subsection{Soil emission}

For a smooth soil surface, the soil microwave emissivity can be well approximated from soil reflectivity $\Gamma_{\mathrm{sP}}$ :

$$
e_{s P}=1-\Gamma_{s P}=1-\left|R_{P}\left(\varepsilon_{S}, \theta\right)\right|^{2}
$$

The reflection coefficient $R_{P}$ can be simply calculated from the soil dielectric permittivity $\varepsilon_{\mathrm{S}}$ and from the view angle $\theta$, using the Fresnel equations $\left(R_{P}=R_{P}\left(\varepsilon_{S}, \theta\right)\right)$. The complex dielectric permittivi- 
ty $\varepsilon\left(\varepsilon=\varepsilon^{\prime}+i \varepsilon^{\prime \prime}\right)$ is a physical characteristic of the material which describes the propagation of an electromagnetic wave in the material. For soils, $\varepsilon_{\mathrm{S}}$ is mainly driven by the soil moisture content and also by the soil textural and structural properties. Several models have been developed in a low frequency range $(1-20 \mathrm{GHz})$ to relate the soil permittivity to soil parameters (soil moisture, bulk density, \% of sand and clay, etc. ) $[15,53]$. At higher frequencies ( $f>20 \mathrm{GHz}$ ), more analyses are required to better characterize the dielectric properties of soils [4].

From equation (1), the emission of a smooth soil can be simply related to soil moisture (through the term $\varepsilon_{S}$ ) and to view angle $\theta$. However, in the general case several factors should be also taken into account. First, surface roughness enhances soil emission and numerous theoretical works have been and are currently developed to relate the soil surface microwave scattering properties to the soil roughness characteristics [18]. For most applications, simple and tractable approaches based on best fit parameters can be used [52].

Also, the microwave radiation penetrates slightly within the ground and volume effects influence soil microwave emission. If there are strong vertical gradients of moisture and temperature within the soil, a question arises: over which soil thickness should we consider surface soil moisture wg and temperature $\mathrm{T}_{\mathrm{S}}$ ? An approximate approach is to consider the mean value of these variables over a fixed soil thickness. This thickness corresponds to the so-called 'sampling depth' $\mathrm{d}_{\mathrm{p}}$, and depends mainly on frequency $\left(\mathrm{d}_{\mathrm{p}} \approx 3 \mathrm{~cm}\right.$ at $1.4 \mathrm{GHz}, \mathrm{d}_{\mathrm{p}} \approx$ $1 \mathrm{~cm}$ at $5 \mathrm{GHz}, \mathrm{d}_{\mathrm{p}} \approx 0.5 \mathrm{~cm}$ if $\left.\mathrm{f}>5 \mathrm{GHz}\right)[26,51]$. It is the layer whose dielectric properties determine the emissivity. To improve characterization of the gradient effects, theoretical and semi-empirical approaches can be applied $[43,61]$.

For most applications, if the soil roughness conditions do not change much during the observations, the emissivity $e_{S P}$ can be considered as monotically decreasing function of soil moisture wg and can be related to it by the general form [54]:

$$
\mathrm{e}_{\mathrm{SP}}=\mathrm{a}_{0}-\mathrm{a}_{\mathrm{l}} \mathrm{wg}
$$

If sufficient ground data are available to calibrate the coefficient $a_{0}$ and $a_{1}$, this simple relationship proved to be very appropriate.

\subsection{Vegetation emission}

At low frequencies ( $f \sim 0.3-2 \mathrm{GHz}$ ), the emission of a vegetation canopy can be well approximated by a simple radiative transfer (R.T.) model, hereafter referred to as the $\tau-\omega$ model. This tractable model is a basic tool to retrieve the surface variables from remote sensed $\mathrm{Tb}_{\mathrm{P}}$ data at low frequencies. At higher frequencies ( $\mathrm{f}>5-10 \mathrm{GHz}$ ), volume scattering effects within the vegetation canopy increase, and more complex R.T. approaches are required to model the canopy microwave emission $[17,49,56]$. Note that coherent effects in the volume scattering cannot be accounted for by the R.T. equations. These effects can be neglected in the high frequency domain when the wavelength is much lower than the scatterer sizes (leaves, branches, trunks, etc.), whereas, at low frequencies, the coherent effects are probably significant, but no tractable approach is currently available to take them into account [28].

Low frequency radiations are better suited for soil moisture monitoring since they can more easily go through the vegetation layer to sense moisture. Therefore we shall focus our analysis on this frequency range. Modelling of vegetation effects at higher frequencies was investigated by Choudhury et al. [11] and Calvet et al. [5].

Using the $\tau-\omega$ model, global emission from the two layer medium (soil and vegetation) is the sum of three terms: $\left(\mathrm{Tb}^{*}\right)$ the direct vegetation emission, $\left(\mathrm{Tb}_{2}\right)$ the vegetation emission reflected by the soil and attenuated by the canopy layer and $\left(\mathrm{Tb}_{3}\right)$ soil emission attenuated by the canopy (figure 1). These different terms can be expressed as:

$$
\text { 1) } \mathrm{Tb}^{*}=(1-\omega)(1-\gamma) \mathrm{T}_{\mathrm{V}} \text {, }
$$

where $T_{V}$ is the vegetation temperature; the single scattering albedo $\omega$ parameterizes scattering within the canopy layer and $\gamma$ is the attenuation factor. This last term is a function of the optical thickness $\tau$ of the canopy and is given by: 
Tb

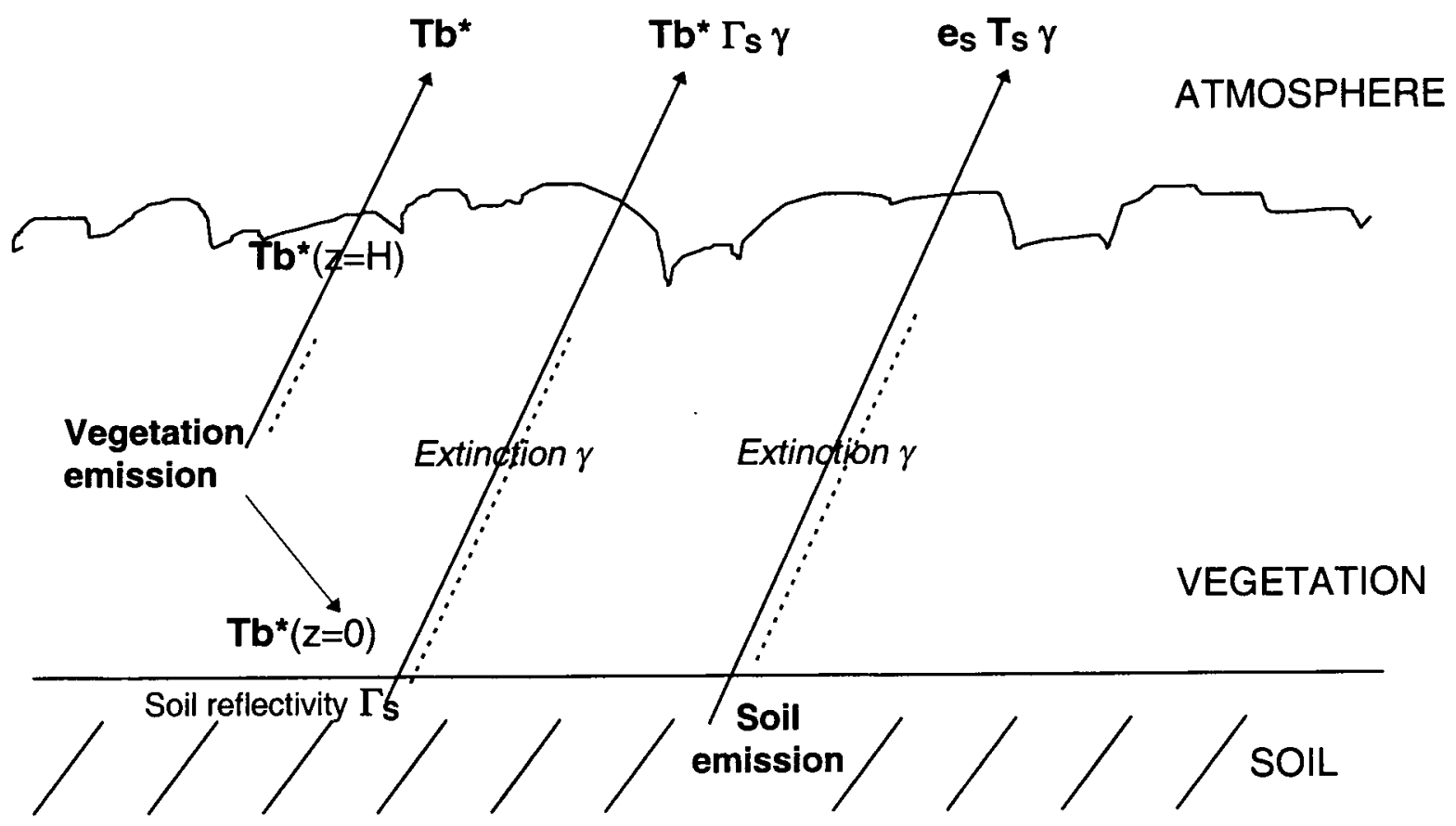

Figure 1. Global emission from the two layer medium (soil and vegetation) resulting from three main contributions: the direct vegetation emission $\left(\mathrm{Tb}^{*}\right)$, the vegetation emission reflected by the soil and attenuated $\left(\mathrm{Tb}_{2}=\mathrm{Tb}^{*} \Gamma_{\mathrm{S}} \gamma\right.$ ), soil emission attenuated by the canopy $\left(\mathrm{Tb}_{3}=\mathrm{e}_{\mathrm{S}} \mathrm{T}_{\mathrm{S}} \gamma\right)$.

$$
\gamma=\exp (-\tau / \cos \theta)
$$

Note that the optical depth $\tau$ is related to the extinction coefficient $\mathrm{Ke}$ according to $\tau=\mathrm{Ke}$. $\mathrm{Hc}$ (Hc = height of canopy)

$$
\text { 2) } \mathrm{Tb}_{2}=\gamma \Gamma_{\mathrm{S}} \mathrm{Tb}^{*}
$$

where $\Gamma_{\mathrm{S}}$ denotes the soil reflectivity depending on soil moisture

$$
\text { 3) } \mathrm{Tb}_{3}=\gamma\left(1-\Gamma_{\mathrm{S}}\right) \mathrm{T}_{\mathrm{S}}
$$

where $\left(1-\Gamma_{S}\right)$ corresponds to soil emissivity $\left(e_{S}=\left(1-\Gamma_{S}\right)\right)$, and $T_{S}$ is the soil temperature.

In order to compute the global canopy emission several simplifications can be made:
Soil and vegetation temperatures are approximately equal $\left(T_{C} \approx T_{S} \approx T_{V}\right)$. Actually, temperature gradient effects within the soil and vegetation layers should be considered. However, neglecting these effects is relevant for most applications to soil moisture study.

$\omega \approx 0$ (scattering effects are almost negligible at $1.4 \mathrm{GHz})$.

Note that this implies that extinction effects are equal to emission effects (extinction coefficient $\mathrm{Ke} \approx$ emission coefficient $\mathrm{Ka}$ ).

The optical thickness $\tau$ can be related to the vegetation biomass. 
We shall briefly analyse this last assertion. Several works found that $\tau$ could be linearly related to the total vegetation water content $\mathrm{W}_{\mathrm{C}}\left(\mathrm{kg} / \mathrm{m}^{2}\right)$ using the so-called b parameter [24]:

$$
\tau=\mathrm{b} \mathrm{W}_{\mathrm{C}}
$$

The $b$ parameter can be calibrated for each crop type or for large categories of vegetation (leaf dominated, stem dominated and grasses. At $1.4 \mathrm{GHz}$ a value of $0.12+/-0.03$ was found to be representative of most agricultural crops. More recent works showed that $b$ also depends on the gravimetric water content of vegetation $[31,58]$. For instance, $b$ for a wheat crop decreased from the value $b=0.125$ for green vegetation down to $b=0.04$ for mature wheat just before harvest [58]. The $b$ parameter depends on temperature, especially at C-band because of the temperature-dependent water relaxation behaviour. Also, it was found that $b$ strongly depends on polarization and incidence angle, especially for vegetation canopies with a dominant vertical structure (stem dominated canopy as cereal crops) $[50,57,59]$.

In summary and using the above simplifications, the global canopy emissivity can be written as:

$$
\mathrm{e}_{\mathrm{P}}=\mathrm{e}_{\mathrm{P}}^{*}\left(1+\gamma_{\mathrm{P}} \Gamma_{\mathrm{SP}}\right)+\left(1-\Gamma_{\mathrm{SP}}\right) \gamma_{\mathrm{P}}
$$

with

$$
\begin{gathered}
\mathrm{e}_{\mathrm{P}}^{*}=\left(1-\gamma_{\mathrm{P}}\right) \\
\gamma_{\mathrm{P}} \approx \mathrm{f} \text { (vegetation biomass) } \\
\left.\Gamma_{\mathrm{SP}} \approx \mathrm{g} \text { (soil moisture } \mathrm{wg}\right)
\end{gathered}
$$

A priori knowledge of the canopy type and possibly of its water status is required to estimate the canopy-dependent parameters of the function $f()\left(b_{p}\right.$ and possibly $\omega_{\mathrm{P}}, \mathrm{C}_{\text {pol }}$ ) in equation (8b). A priori knowledge of the soil type is also required to estimate or calibrate the function $g()$ in equation $(8 \mathrm{c})$. From this information and using equation (8), simple modelling of the canopy brightness $\mathrm{Tb}_{\mathrm{p}}$ can be computed from three land surface variables of interest: soil moisture wg, vegetation biomass and canopy temperature $T_{C}\left(T_{C} \approx T_{S} \approx T_{V}\right)$. The emissivity is sensitive to other characteristics of the environment (soil surface roughness, topography, soil texture, vegetation structure, etc.) but these dif- ferent terms can be considered as rather stable with time, and thus can be estimated or calibrated from ancillary information (soil maps, high spatial resolution data in the optical domain, digital elevation model, etc.).

\section{MICROWAVE TECHNIQUES}

The current status of the microwave techniques and future developments are presented in this section. Note that in this paper we shall focus on the use of low frequency measurements for two main reasons: at higher frequencies ( $>15 \mathrm{GHz}$ ) 1) screening effect of vegetation is significant and retrieval of soil and vegetation hydrological characteristics is difficult in most applications; 2) corrections of the atmospheric effects are required and it strongly limits one of the key interests of microwave remote sensing. However, several recent works investigated the microwave signatures of the land surfaces at high frequencies [27, 41]. In that frequency range, satellite data are currently in operational use for atmospheric parameter retrieval over oceans. For atmospheric applications, if the land surface contribution to microwave radiances could be determined accurately enough, then microwave retrievals of atmospheric quantities (cloud liquid water and precipitations), now performed only over oceans, might be extended to land areas.

\subsection{Requirements for the configuration system}

As discussed in the preceding sections, the microwave measurement is sensitive to three main land surface variables: $w g, \mathrm{~W}_{\mathrm{C}}$ and $\mathrm{T}_{\mathrm{C}}$ (assuming that the other factors are parameters that can be calibrated using ancillary information). Therefore several measurement data $m_{i},(i=1, n)$, with a significant low level of correlation, are required to discriminate between the effects of the surface data. These data can be obtained from measurements for several configuration systems of the sensor in terms of polarization, view angle and frequency. 
As for polarization effects, the microwave signatures of soil and vegetation exhibit distinct responses. Emission from bare soil is strongly polarized $\left(\mathrm{Tb}_{\mathrm{H}}<\mathrm{Tb}_{\mathrm{V}}\right)$ when view angle $\theta$ exceeds $30^{\circ}$, while the emission from a dense vegetation cover exhibits almost no polarization pattern $\left(\mathrm{Tb}_{\mathrm{H}} \approx \mathrm{Tb} \mathrm{V}_{\mathrm{V}}\right)$. This property has been often used to monitor the vegetation development $[8,11,48]$.

Also, multi-frequency measurements can be useful to distinguish soil contribution from that of vegetation. At low frequencies ( $\mathrm{f} \sim 1.4 \mathrm{GHz}$ ), soil contribution is the dominant term in equation (8) for most low vegetation covers $(\gamma \approx 1)$. As frequency increases, the screening effect of vegetation, i.e. the intensity of the attenuation effect of soil contribution by the canopy layer, increases $(\gamma \approx 0)$. Thus at $5 \mathrm{GHz}$, for a low vegetation cover, soil and vegetation contributions are close in magnitude, while at $10 \mathrm{GHz}$ the vegetation effect becomes dominant (figure 2). Note that as attenuation effects of soil contribution increase, vegetation emission also increases (extinction coefficient $\mathrm{Ke} \approx$ emission coefficient Ka). Therefore, the 'screening effect' due to vegetation combines two effects: 1) the increase in the attenuation of the soil contribution and 2) the increase in the emission from the vegetation.

Different levels in the magnitude of this vegetation 'screening effect' can be obtained from multifrequency measurements. Similar results can be obtained from multi-angular measurements, since the attenuation effects increase as view angle increases $(\gamma=\exp (-\tau / \cos \theta))$. The data obtained from a multi-configuration system are appropriate to distinguish soil contribution from that of vegetation.

\subsection{Sensor systems}

The most well-known spaceborne sensors are SMMR (1978-1987) and SSM/I. The latter has been in operation on the DMSP satellite since 1987 [23]. The European sensor MIMR $(6.8,10.65,18.7$, $23.8,36.5$ and $89 \mathrm{GHz}$ ), with a much improved resolution and calibration is scheduled for launch in the year 2000 [37]. Using a parabolic reflector of dimension $1.6 \mathrm{~m} \times 1.4 \mathrm{~m}$, the ground resolution of MIMR is about $50 \mathrm{~km}$ at C-band $(-5 \mathrm{GHz})$. The conical scan geometry of the radiometer results in a

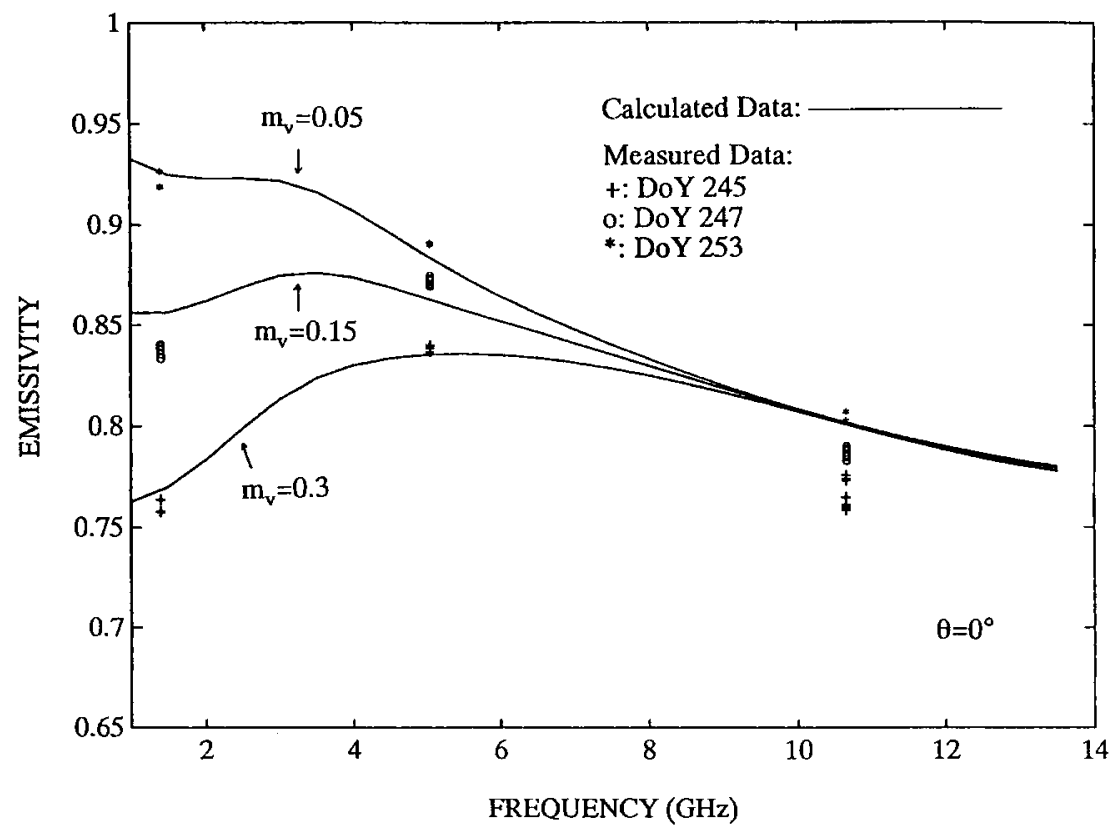

Figure 2. Microwave emissivity of a soybean crop versus frequency, for three levels of soil moisture $(\mathrm{mv}=$ $0.05,0.15$ and $0.3 \mathrm{~m}^{3} / \mathrm{m}^{3}$ ). PORTOS93 experimental results $(+, 0, *)$ and theoretical simulations $(-)$ are shown (from Wigneron et al. [56]). 
daily coverage of $80 \%$ of the earth surface with an incidence angle of $50^{\circ}$. Other spaceborne existing/near future instruments have very similar characteristics: AMSR (for deployment on the Japanese satellite ADEOS-II), PM-1 AMSR (USA), Baskhara II (India). Operational use of these sensors concern mostly retrieval of atmospheric characteristics (temperature, water vapour, cloud liquid, etc.), sea-surface temperature and wind, sea-ice and snow cover [36]. Since all frequency bands exceed $5 \mathrm{GHz}$, screening effect of vegetation is significant, and monitoring of soil moisture is limited to sparse vegetation of arid and semi-arid areas.

At satellite altitudes, an antenna size of at least $10 \mathrm{~m}$ is required to obtain resolution in the $10-20$ $\mathrm{km}$ range from a low frequency (L-band) instrument (the resolution is inversely proportional to the wavelength $\lambda$ and proportional to the antenna diameter (figure 3a)). Therefore, at the moment, L-band data are available only from ground or airborne instruments. Such instruments have been developed in several countries (Russia, USA, India, Finland, Switzerland, Italy, France) for remote sensing of the land surface features. In France, the multifrequency PORTOS instrument $(1.4,5,10.65,23.8,36.5$ and
$90 \mathrm{GHz}$ ) has been intensively used in several airborne and field campaigns. In the USA, the Pushbroom Microwave Radiometer (PBMR) and ESTAR 1.4 GHz instruments [45] have been involved in most of the large scale field experiments: FIFE, Monsoon-90, Washita'92, Hapex Sahel, Southern Great Plains 1997 Hydrology Experiment (SGP97). An analysis of the results obtained from these three instruments is given in the next section.

Besides conventional antenna technology, an alternative consists in synthesizing large aperture using an array of small antenna elements. This principle is called aperture synthesis or interferometric radiometry $[20,44]$. The antenna consists of elementary radiating elements (ERE) installed on deployable arms arranged in $\mathrm{T}$ or $\mathrm{U}$ shape figure $3 b$ ). These depoyable antennas can be easily implemented in space and can achieve the same resolution of very large conventional antennas, without the associated mass. Several one-dimensional (one arm) or two-dimensional synthetic aperture L-band radiometer have been developed and tested (ESTAR in the USA [32], MIRAS in France [20]). In particular, the airborne ESTAR radiometer was evaluated
Conventionnal Antenna $\beta \sim \lambda / D$

a)

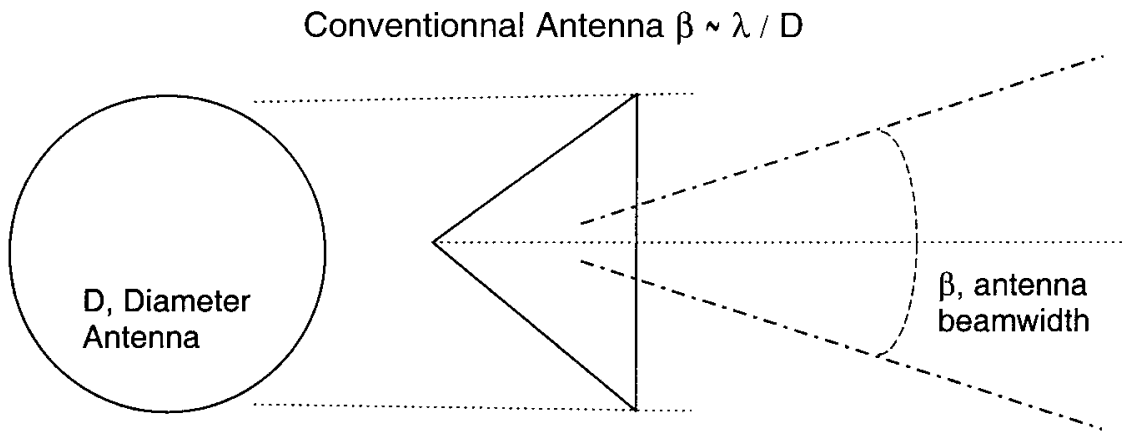

\section{ERE}

b)

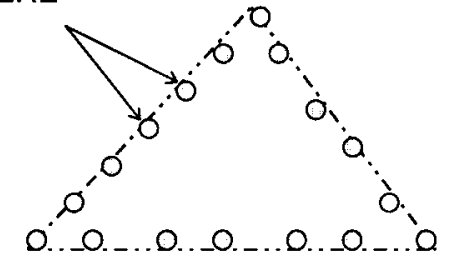

Aperture Synthesis Antenna $=$ Assembling Elementary Radiating Elements (ERE)
Figure 3. Conventional parabolic antenna characteristics (a) and aperture synthesis antenna consisting of elementary radiating elements (ERE) installed on deployable arms (b). 
for soil moisture mapping applications in several large scale experiments [45].

In 1996, two L-band space instruments were proposed to the Earth System Science Program, in response to an NASA Annoucement of Opportunity. They were: IRIS (Inflatable Radiometric Imaging System) and Hydrostar (based on the heritage of synthetic aperture ESTAR technology). The proposals proceeded to step 2 of the selection process. The two US projects clearly show that 1) new technology approaches have now the potential of providing remote sensed L-band data with adequate resolution and being compatible with satellite platform limitations; 2) soil moisture is one of the priority global environment variables for regional/global weather forecast models (at spatial resolutions $\sim 20-100 \mathrm{~km})$ and long-range climate simulation models (at $\sim 150-200 \mathrm{~km}$ ).

\section{LAND SURFACE MONITORING}

The models described in the first section of this paper are very appropriate tools to quantify the sensitivity of the remote sensing signal to the surface variables. Also from model inversion, retrieval methods are developed to compute estimates of the surface variables and to map soil moisture. Several measurement data, acquired from several configuration systems of the sensor are often required in the retrieval process. The first part of this section reviews retrieval approaches and the most significant results.

Estimates of surface soil moisture resulting from the inversion process can be used in the fields of meteorology and hydrology in order to control model simulations and improve water and energy flow forecasting. Also, assimilation techniques based on modelling of the water and mass transfers in the soil column, can be used to estimate the water content down to depths beyond the sampling depth of the L-band microwave R-S observations. These aspects are presented and discussed in the second part of this section.

\subsection{Retrieval studies: methods and results}

Very significant examples of the capability of microwave radiometry to produce soil moisture database for hydrologic studies can be illustrated by the works of the USDA Hydrology Laboratory (Beltsville) in relation with the NASA Goddard Space Flight Center (Greenbelt) during large scale experiments. For instance, during four intensive field campaigns of FIFE in May-October 1987, the PBMR was used to map surface soil moisture [55]. It was also used to map surface soil moisture during the Monsoon 90 experiment in southern Arizona [45]. Similarly, the ESTAR instrument was used to map soil moisture over the Washita' 92 study area (46 by $19 \mathrm{~km}$ ) with $200 \mathrm{~m}$ resolution in central Oklahoma [25]. In this region, land cover is dominated by rangeland and pasture. During the intensive observation period, a consistent day-to-day decrease in soil moisture corresponding to a drying phase could be monitored. Predictions of soil moisture were analysed using several verification sites, where ground-based $0-5 \mathrm{~cm}$ surface soil moisture samples were collected. Distinct spatial structures, in relation with topography, soil texture and soil hydraulic properties could be distinguished by tracking soil moisture changes during drying [35].

Airborne microwave radiometry was also used over semi-arid areas, in the framework of the Hapex-Sahel Experiment using both the PORTOS and PBMR instruments [8]. Maps of soil moisture were computed at several dates during a month period in the middle of the rainy season. Soil moisture in the top $5 \mathrm{~cm}$ was calculated using a single linear relationship between the brightness temperature measurements from PBMR, averaged within $200 \mathrm{~m}$ grid square cells, and soil moisture. Large contrasts in soil moisture maps can be seen in figure 4 between DoY 238 (observations during a rainy period) and DoY 248 (5 days after rain). The spatial patterns of soil moisture can be explained by both the heterogeneity of the rainfall amounts, which was shown to be a major characteristic of the Sahelian rain fields, and by soil hydrodynamic properties which may affect the drainage rate. As 

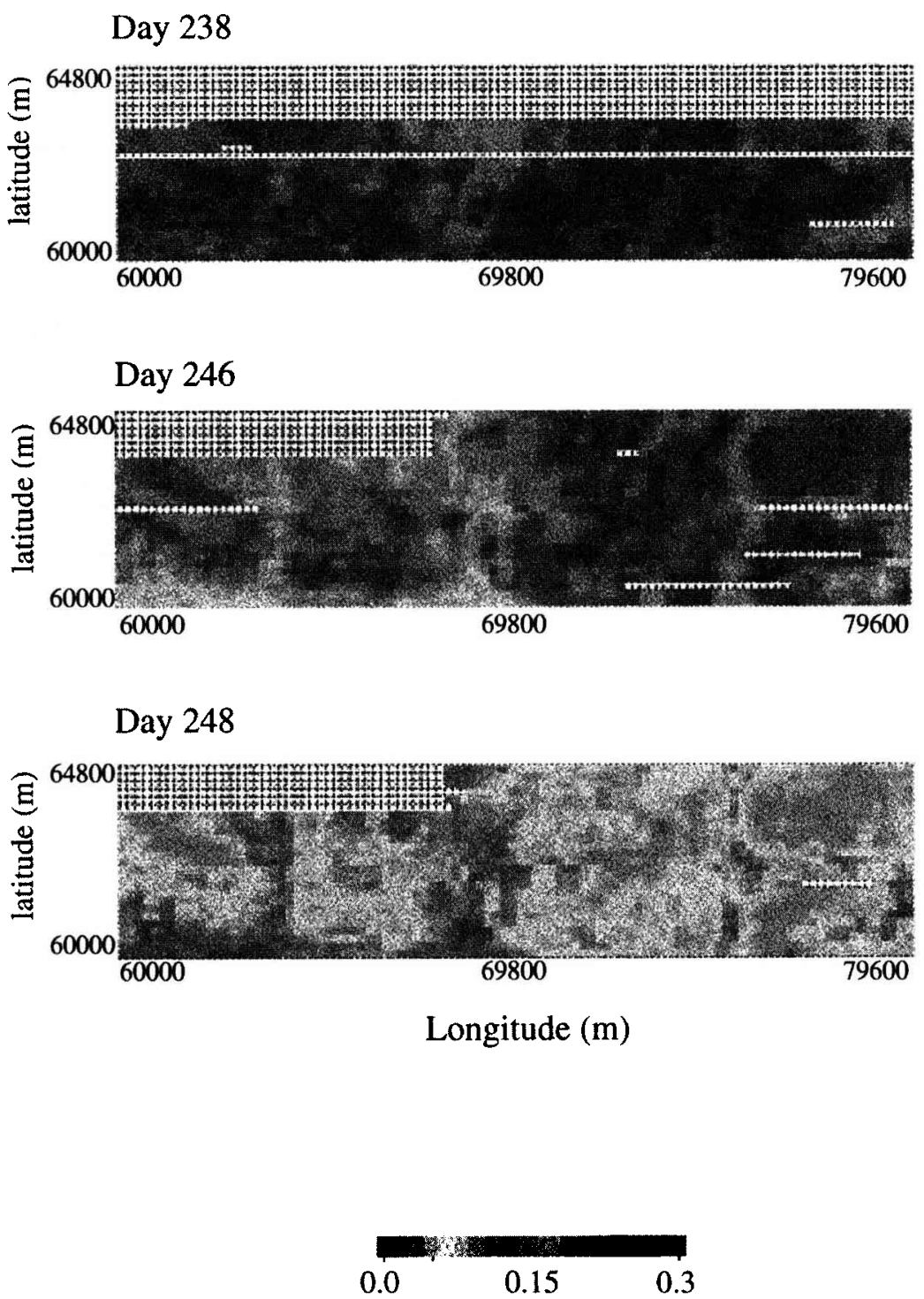

\section{Humidité du sol $\left(\mathrm{m}^{3} / \mathrm{m}^{3}\right)$}

Figure 4. Soil moisture maps during the Hapex-Sahel Experiment using the PBMR on DoY 238, DoY 246 and DoY 248 (from Chanzy et al. [8]). for the Washita'92 experiment, these drying patterns were used to characterize soil properties [22].

In these different works, the retrieval algorithm used to produce the soil moisture maps is based on the $\tau-\omega$ model, using ancillary data for surface temperature and vegetation characteristics. Temperature estimates were usually obtained from thermal infrared measurements acquired concurrently with the microwave observations. Vegetation data (type and water content) were estimated using land-use database and SPOT images. A single vegetation water content value, estimated from ground observations, was assigned to each vegetation category. It seems that the way to account for the vegetation characteristics limits the applicability of this approach for operational use of radiometric data in global study. For instance, Chen et al. [9] investigated the spatial distribution and pattern persistence 
of surface soil moisture from remote sensing, using the PBMR during the FIFE experiment. Results indicated that more work is needed to improve understanding of a number of factors, such as vegetation, thatch layer and surface slope, which affect the accuracy of the PBMR retrieved soil moisture.

In order to better account for vegetation effects, the possibility of simultaneously retrieving soil moisture and vegetation water content $\mathrm{W}_{\mathrm{C}}$ from multi-configuration passive measurements has been investigated by Wigneron et al. $[57,58]$ and Chanzy et al. [8]. Chanzy et al. [8] estimated $W_{C}$ from indices at $\mathrm{C}$-band based on polarization and angular differences over a semi-arid area in Sahel. Similarly, Teng et al. [48] used the polarization difference from satellite data to estimate the vegetation effects and parameterize the linear relationship between soil moisture and brightness temperature. The study area included part of the US corn and wheat belts. Over agricultural crops (wheat and soybean) Wigneron et al. [57, 58] showed that multi-angular data at $1.4 \mathrm{GHz}$ or bi-frequency data (at 1.4 and $5 \mathrm{GHz}$ ) can be used to retrieve simultaneously soil and vegetation characteristics (figure 5 ). The principle of these approaches is to use measurements corresponding to two values of the vegetation attenuation factor, which parameterizes the canopy 'screening effect'. Note that similar results in discrimination can probably also be obtained from combined passive/active data. The possibility of making simultaneous estimates of the soil and vegetation characteristics, as demonstrated in these works, reinforces the strong potential interest for an operational use of the microwave radiometric data.

Though optimum frequency for soil moisture study is $1.4 \mathrm{GHz}$, interesting results have been obtained at higher frequencies from spaceborne sensors.

Thus, it is important to mention the study of Teng et al. [48] from SSM/I data, and those of Choudhury and Golus [10], Owe et al. [40], Ahmed [1] from SMMR data. For instance, Ahmed [1] obtained six levels of soil moisture in the mid-west and southern United States from 6.6 GHz SMMR observations.
As for surface temperature, simultaneous retrievals of soil moisture and surface temperature have been attempted by Calvet et al. [5] over sparse vegetation covers. It seems that retrievals of surface temperature should be limited to rather dense vegetation covers, forests in particular, where the microwave emissivity remains relatively constant with time $[3,21,34,60]$. From satellite data, it appears that temperature retrieval requires accurate estimates of the fractional area of open water, within each footprint. In the Swiss Central Plains, typical RMS errors between measured and estimated surface temperatures are between 2 and $4 \mathrm{~K}$ from $\mathrm{SSM} / \mathrm{I}$ data [21]. Conversely, in nonforested regions surface emittance data show the potential for flood-monotoring purposes [27].

\subsection{Use of temporal soil moisture information}

Soil moisture is an important variable in many hydrologic, agricultural and meteorological applications. As presented in the Introduction, the distribution of soil water within the $0-10 \mathrm{~mm}$ or $(0-50$ $\mathrm{mm}$ ) layer has a strong influence on soil evaporation. Taking into account the evaporative demand, reasonable estimates of cumulative evaporation from soil can be obtained from simple models based on a surface resistance $r_{S}$. The functional relationships between $r_{S}$ and near-surface soil water content has been studied in many works [7, 13, 33].

For instance, working with PBMR data from Monsoon 90, Kustas et al. [30] showed that the evaporative fraction, i.e. the fraction of available energy which goes into evaporation, was strongly correlated, $r^{2}=0.7$, with the observed microwave brightness temperatures. While we would expect this to be the case for the sparsely vegetated Walnut Gulch watershed, the remotely sensed soil moisture values also appear to be important in the more humid grassland site of FIFE. In an analysis of the FIFE-89 data for the surface area averaged fluxes, Sellers et al. [47] found that the remotely sensed surface soil moisture from the PBMR is very important for parameterizing the soil resistance to evaporation and for estimating the soil profile moisture 


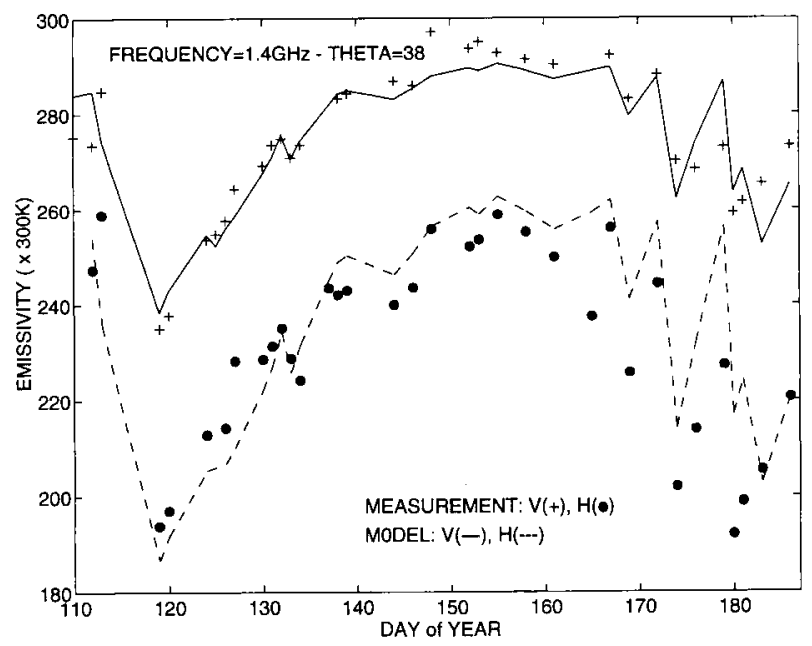

a.

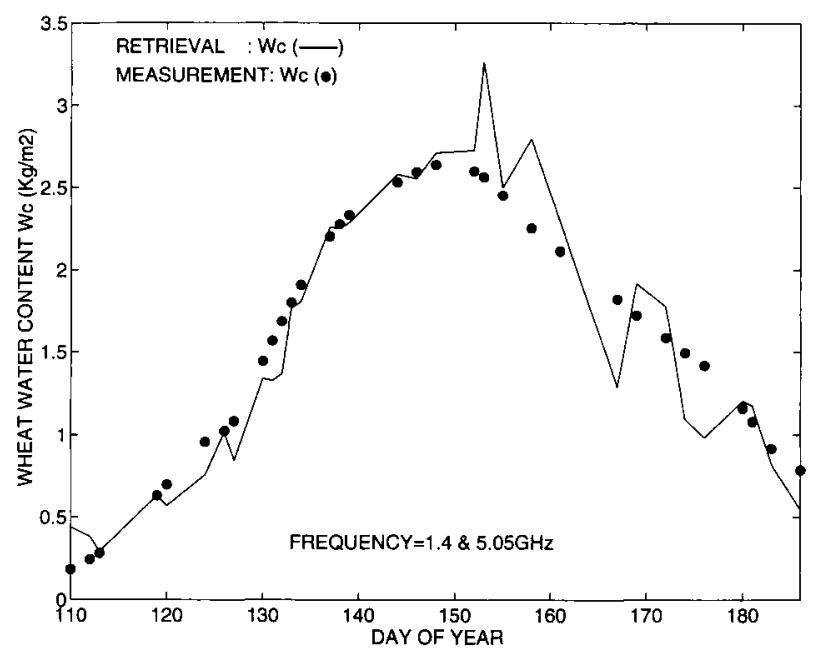

c.

content. Using the spatial variation of soil moisture from the PBMR in their Simple Biosphere model (SiB) they found that it accounted for about a third of the variance observed in the latent heat flux.

The soil moisture content is also important for predicting runoff following a rain event. In Monsoon 90 the PBMR estimates of $0-5 \mathrm{~cm}$ soil moisture were used for the definition of the prestorm initial soil moisture conditions for an event based rainfall-runoff model [19]. The findings of this study indicated that the remotely sensed measures of soil moisture were as good as several

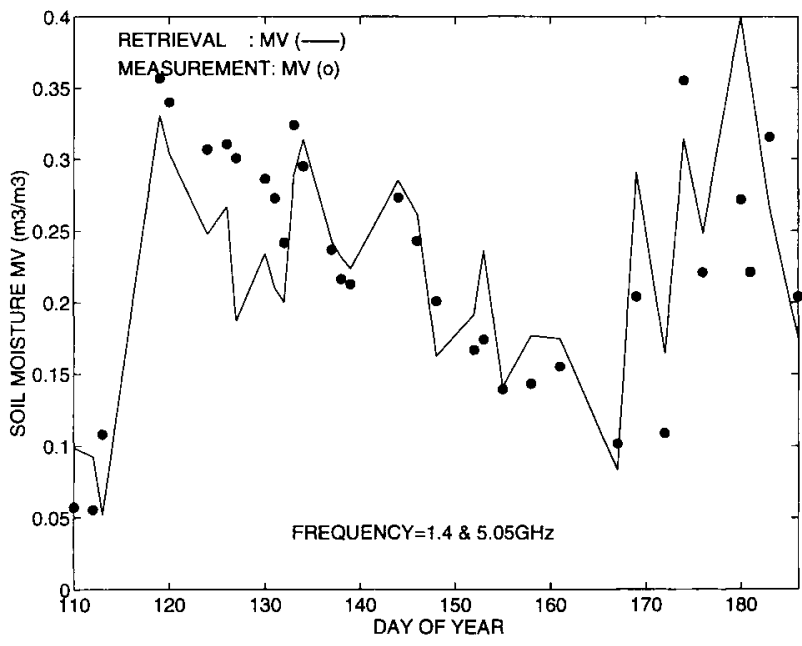

b.

Figure 5. PORTOS-93 experiment: microwave mesurements at $1.4 \mathrm{GHz}$ during the crop cycle (a) and retrieval of the surface variables from bi-frequency 1.4 and $5 \mathrm{GHz}$ data (soil moisture $w g(b)$ and vegetation water content $W_{C}(c)$ ) (from Wigneron et al. [57]).

ground based methods in a small watershed for runoff predictions. Similarly, cartography of the spatial variations of soil moisture and evapotranspiration at the river basin scale, were used to initialize hydrological models and improve outflow forecasting $[12,62]$. Thus, it should be possible to use the remotely sensed measures in areas without extensive ground measurements to improve the prediction of runoff.

In the field of meteorology, potential interest of repetitive estimates of soil moisture, on a 1,5 day basis, to calibrate and initialize land surface transfer 
schemes in mesoscale atmospheric models, has been analysed by Noilhan and Calvet [38]. Several works investigated the ability to assess the hydrological conditions at depth within soil (in the top 1 or $2 \mathrm{~m}$ ) from repetitive estimates of the water content at the soil surface. In particular, the water content in the root zone w2 is an important parameter, which associated with the depth of the root zone, can be used to assess the water status of vegetation and water availablility for plant transpiration processes. Promising results of estimates of soil characteristics at depth have been obtained from assimilation techniques based on modelling of the water and mass transfers in the soil column.

For instance, the information content of the time variations of surface soil moisture during a 5-30 day period has been analysed in several works [6, $16,42]$. A simple water budget for wg can be derived from the force-restore method applied by [14] to the ground soil moisture:

$$
\delta w g / \delta t=-C_{1}\left(E_{S}-P\right) / d_{1}-C^{2}(w g-w 2) / \tau
$$

The first term on the right of equation (9) represents the influence of surface atmospheric fluxes (outputs due to evaporation $\mathrm{E}_{\mathrm{S}}$ and inputs due to precipitation $\mathrm{P}$ ). The second term in equation (9) characterizes the diffusivity of water in the soil which tends to restore wg toward the bulk value (w2). The dimensionless coefficients $\mathrm{C}_{1}$ and $\mathrm{C}_{2}$ are highly dependent upon soil moisture (wg and $w 2$ ) and soil texture. They can be calibrated from measurements or estimated using parameterizations derived from numerical experiments [39].

Equation (9) relates the time variations of surface soil moisture wg to the parameters of interest, $\mathrm{E}_{\mathrm{S}}, \mathrm{P}$ and w2. If correct estimations of $P$ can be obtained from the ground meteorological network, periodic observations of wg will provide information on the root zone water content $\mathrm{w} 2$. On this basis, retrieval of the root zone soil moisture has been carried out by Calvet et al. [6] during the Murex experiment. The study is based on a continuous series of micrometeorological data measured in south-western France on a fallow site in 1995-1996. A meteorological surface scheme (ISBA) including a force-restore modelling of water and heat transfers in soil, was used to retrieve variables at depth from the ground measurements of wg. It was found that one measurement of wg every 3-4 days during a minimum 15 day period, was sufficient to obtain accurate estimates of w2 (figure 6).

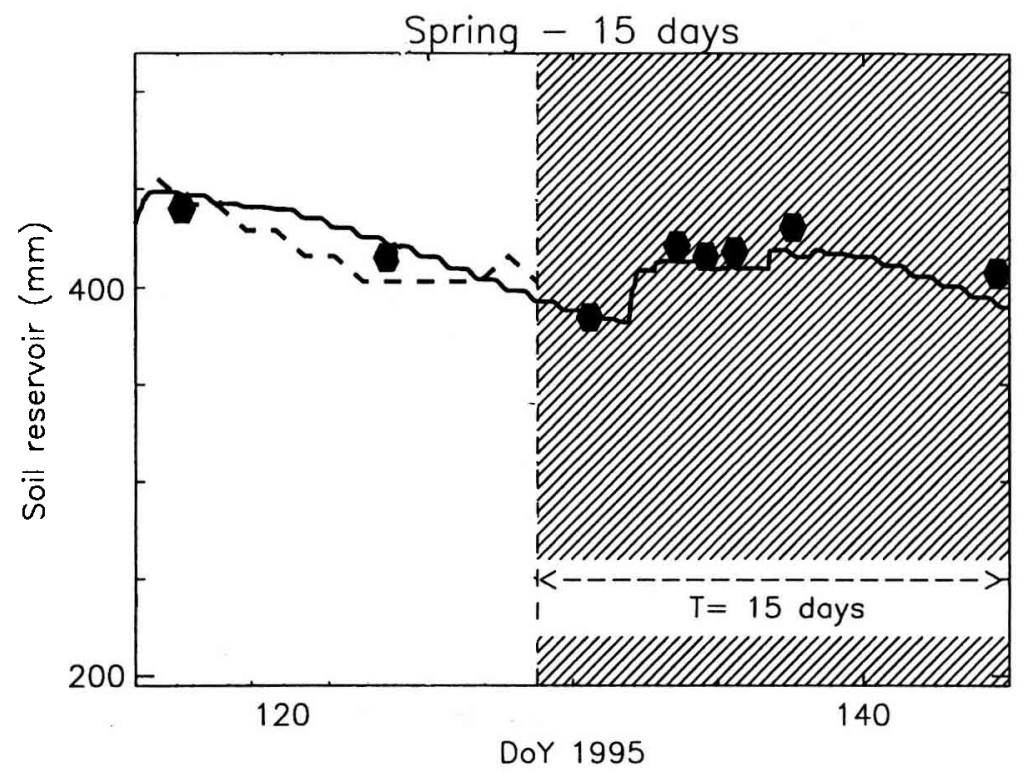

Figure 6. MUREX-96 experiment: retrieved total soil water content (dashed thick line) using a 15 day surface soil moisture measurement series, compared with ISBA simulations (solid thick line) and the observations (dark points) (from Calvet et al. [8]). 
In parallel, the feasibility of using brightness temperature measurements (microwave and infrared channels) to solve the inverse problem associated with soil moisture and heat profile was demonstrated by Entekhabi et al. [16]. This theoretical analysis was based on a Kalman filter using radiative transfer and coupled moisture and heat diffusion equations. Both assimilation approaches from Calvet et al. [65] and Entekhabi et al. [16] showed that periodic observations of the surface characteristics, such as those provided by microwave remote sensing systems, can be used to retrieve information on the lower layers. Additional work in the future is necessary to test the conditions for an operational use of such assimilation techniques in atmospheric and hydrological models at a regional scale. However, these works open promising new fields of investigation and strongly emphasize the large potential interest of repetitive remotely sensed microwave signatures, on a 1,3 day basis.

\section{CONCLUSION}

The previous sections have discussed the basis of passive microwave remote sensing for soil moisture, and indicated the key role of this surface variable in the water exchanges between the surface and the atmosphere. In the last section, recent assimilation techniques of periodic surface data are presented and proved to be very promising for deriving important geophysical parameters, such as the root zone soil moisture.

As promising as passive microwave remote sensing for soil moisture appears to be, the future for using this technique is still uncertain. Existing and near future instruments do not have frequencies low enough to be useful for soil moisture retrieval, except over arid or semi-arid areas where the screening effect of vegetation is low. Currently, there is no planned passive spaceborne system including a low frequency channel (L-band). Furthermore, it seems that multispectral (L-band and C-band for instance) or multi-incidence data are required to discriminate between the effects of soil moisture and vegetation biomass. Large interest in near future instruments (e.g. MIMR and AMSR) over the land surface should concern mostly surface temperature retrieval.

However, using aperture synthesis, current technology has now the potential to develop spaceborne L-band sensors with a spatial resolution on the order of $10 \mathrm{~km}$. Therefore, providing much needed data for the computational cells of meteorological and climate models on the order of $10-200 \mathrm{~km}$ is well within the capacity of such future passive systems. Also, during the last decade, there has been increasing evidence of a large atmospheric sensitivity to land surface processes. Short-term forecasts are highly dependent on initial surface conditions and the soil moisture status is a key information to predict the near-surface atmospheric fields. In summary, passive microwave radiometry appears to be a promising tool that addresses the fundamental needs in atmospheric and hydrological models for land surface characterization at a regional/global scale on a daily basis.

\section{REFERENCES}

[1] Ahmed N.U., Estimating soil moisture from 6.6 $\mathrm{GHz}$ dual polarization, and/or satellite derived vegetation index, Int. J. Remote Sens. 16 (1995) 687-708.

[2] Brisson N., Perrier A., A semiempirical model of bare soil evaporation for crop simulation models, Water Resour. Res. 27 (1991) 719-727.

[3] Calvet J.-C., Wigneron J.-P., Mougin E., Kerr Y.H., Brito J.L., Plant water content and temperature of the Amazon forest from satellite microwave radiometry, IEEE Trans. Geosci. Remote Sens. 32 (1994) 397-408.

[4] Calvet J.-C., Wigneron J.-P., Chanzy A., Raju S., Laguerre L., Microwave dielectric properties of a silt-loam at high frequencies, IEEE Trans. Geosci. Remote Sens. 33 (1995) 634-642.

[5] Calvet J.-C., Wigneron J.-P., Chanzy A., Haboudane D., Retrieval of surface parameters from microwave radiometry over open canopies at high frequencies, Remote Sens. Environ. 53 (1995) 46-60.

[6] Calvet J.-C., Noilhan J., Bessemoulin P., Retrieving the root-zone soil moisture from surface soil moisture or temperature estimates: a feasibility study 
based on field measurements, J. Appl. Meteorol. (1998) in press.

[7] Chanzy A., Bruckler L., Significance of soil surface moisture with respect to daily bare soil evaporation, Water Resour. Res. 29 (1993) 1113-1125.

[8] Chanzy A., Schmugge T.J., Calvet J.C., Kerr Y., van Oevelen P., Grosjean O., Wang J.R., Airborne microwave radiometry on a semi-arid area during Hapex-Sahel, J. Hydrol. 188-189 (1997) 285-309.

[9] Chen D., Engman E.T., Brutsaert W., Spatial distribution and pattern persistence of surface soil moisture and temperature over prairie from remote sensing, Remote Sens. Environ. 61 (1997) 347-360.

[10] Choudhury B.J., Golus R.E., Estimating soil wetness using satellite data, Int. J. Remote Sens. 9 (1988) 1251-1257.

[11] Choudhury B.J., Wang J.R., Hsu A.Y., Chien Y.L., Simulated and observed $37 \mathrm{GHz}$ emission over Africa, Int. J. Remote Sens. 11 (1990) 1837-1868.

[12] Cognard A.-L., Loumagne C., Normand M., Ottlé C., Vidal-Madjar D., Vidal A., Soil moisture and hydrological modelling using radar and optical remote sensing: a case study in Brittany (France), in: Proceedings of the Second ERS Applications Workshop, London, UK (ESA SP-383, Feb 1996), 1996, pp. 153-160.

[13] Daamen C.C., Simmonds L.P., Measurement of evaporation from bare soil and its estimation using surface resistance, Water Resour. Res. 32 (1996) 1393-1402.

[14] Deardorff J.W., A parameterization of groundsurface moisture content for use in atmospheric prediction model, J. Appl. Meteorol. 16 (1977) 1182-1185.

[15] Dobson M.C., Ulaby F.T., Hallikainen M.T., El-Reyes M.A., Microwave dielectric behavior of wet soil - Part II: Dielectric mixing models, IEEE Trans. Geosci. Remote Sens. 23 (1985) 35-46.

[16] Entekhabi D., Nakamura H., Njoku E.G., Solving the inverse problem for soil moisture and temperature profiles by sequential assimilation of multifrequency remotely sensed observations, IEEE Trans. Geosci. Remote Sens. 32 (1994) 438-447.

[17] Ferrazzoli P., Guerriero L., Passive microwave remote sensing of forests: a model investigation, IEEE Trans. Geosci. Remote Sens. 34 (1996) 433-443.

[18] Fung A.K., Microwave Scattering and Emission Models and their Applications, Artech House, Norwood, MA, 1994.
[19] Goodrich D.C., Schmugge T.J., Jackson T.J., Unkrich C.L., Keefer T.O., Parry R., Amer S., Runoff simulation sensitivity measurements to remotely sensed initial soil water content, Water Resour. Res. 30 (1994) 1393-1405.

[20] Goutoule J.M., MIRAS spaceborne instrument and its airborne demonstator, in: Proceedings of the Consultative meeeting on Soil Moisture and Ocean Salinity (SMOS), ESTEC, Nordwiik, The Netherlands, ESA WPP-87, 1995, pp. 65-70.

[21] Hiltbrunner D., Land surface temperature and microwave emissivity from SSM/I data, Ph. D. thesis, Universität Bern, 1996.

[22] Hollenbeck K.J., Schmugge T.J., Hornberger G.M., Wang J.R., Identifying soil hydraulic heterogeneity by detection of relative change in passive microwave remote sensing observations, Water Resour. Res. 32 (1996) 139-148.

[23] Hollinger J.P., Peirce J.L., Poe G.A., SSM/I instrument evaluation, IEEE Trans. Geosci. Remote Sens. 28 (1990) 781-790.

[24] Jackson T.J., Schmugge T.J., Vegetation effects on the microwave emission of soils, Remote Sens. Environ. 36 (1991) 203-212.

[25] Jackson T.J., Le Vine D.M., Swift C.T., Schmugge T.J., Schiebe F.R., Large area mapping of soil moisture using the ESTAR passive microwave radiometer in Washita'92, Remote Sens. Environ 53 (1995) 27-37.

[26] Jackson T.J., O’Neill P.E., Swift C.T., Passive microwave observation of diurnal surface soil moisture, IEEE Trans. Geosci. Remote Sens., vol. 35, no. 5, 1997, pp. 1210-1221.

[27] Jones A.S., Vonder Haar T.H., Retrieval of microwave surface emittance over land using coincident microwave and infrared satellite measurements, J. Geophys. Res. 102, 13, 609-13, 626. (1997)

[28] Kerr Y.H., Wigneron J.P., Vegetation models and observations - A review, in: Choudhury B., Kerr Y., Njoku E., Pampaloni P. (Eds.), Passive Microwave Remote Sensing of Land-Atmosphere Interactions, ESA/NASA International workshop - 1993 (Saint-Lary), VSP, Utrecht, 1994, pp. 317-344.

[29] Kerr Y., Chanzy A., Wigneron J.-P., Schmugge T.J., Laguerre L., Requirements for assessing soil moisture from space in arid and semi arid areas, in: Proceedings of the Consultative meeting on Soil Moisture and Ocean Salinity (SMOS), ESTEC, ESA WPP-87, Nordwiik, The Netherlands, 1995, pp. 15-33. 
[30] Kustas W.P., Schmugge T.J., Humes K.S., Jackson T.J., Parry R., Weltz M.A., Moran M.S., Relationships between evaporative fraction and remotely sensed vegetation index and microwave brightness temperature for semiarid rangelands, J. Appl. Meteorol. 32 (1993) 1781-1790.

[31] Le Vine D.M., Karam M.A., Dependence of attenuation in a vegetation canopy on frequency and plant water content, IEEE Trans. Geosc. Remote Sens. 34 (1996) 1090-1096.

[32] Le Vine D.M., Griffis A.J., Swift C.T., Jackson T.J., ESTAR: A Synthetic aperture Microwave Radiometer for Remote Sensing applications, Proc. IEEE 82 (1994) 1787-1801.

[33] Mahfouf J.F., Noilhan J., Comparative study of various formulations of evaporation from bare soil using in situ data, J. Appl. Meteorol. 30 (1991) 1354-1365.

[34] McFarland M.J., Miller R.L., Neale C.M., Land surface temperature derived from the SSM/I passive microwave brightness temperature, IEEE Trans. Geosci. Remote Sens. 28 (1990) 839-845.

[35] Mattikalli N.M., Engman E.T., Ahuja L.R., Jackson T.J., Estimating soil properties from microwave measurements of soil moisture, in: Proc. SPIE, Conf. on Remote Sensing for Agriculture, Forestry, and Natural Resources, Paris, France, vol. 2585, 1995, pp. 89-101.

[36] Mätzler C., COST 712: Application of microwave radiometry to atmospheric research and monitoring, Report from Review Workshop of Project 1, EUMETSAT, Darmstadt, Germany, 1997.

[37] Menard Y. (1995) The design of the ESA multifrequency imaging microwave radiometer (MIMR), in: Choudhury B.J., Kerr Y., Njoku E., Pampaloni P. (Eds.), Passive Microwave Remote Sensing of LandAtmosphere Interactions, ESA/NASA International Workshop 1993 (St Lary), VSP, Utrecht, 1995, pp. 637646

[38] Noilhan J., Calvet J.-C., Mesoscale land-atmosphere models and data needs, in: Choudhury B.J., Kerr Y., Njoku E., Pampaloni P. (Eds.), Passive Microwave Remote Sensing of Land-Atmosphere Interactions, ESA/NASA International Workshop 1993 (St Lary), VSP, Utrecht, 1995, pp. 17-54.

[39] Noilhan J., Planton S., A simple parameterization of land surface processes for meteorological models, Mon. Weather Rev. 117 (1989) 536-549.

[40] Owe M., van de Griend A.A., Chang A.T.C., Surface soil moisture and satellite microwave observations in semiarid southern Africa, Water Resour. Res. 28 (1992) 829-839.
[41] Prigent C., Rossow W.B., Matthews E., Microwave land surface emissivities estimated from SSM/I observations, J. Geophys. Res. 102, D18, (1997) $21867-21890$.

[42] Ragab R., Towards a continuous operational system to estimate the root-zone soil moisture from intermittent remotely sensed surface moisture, J. Hydrol. 173 (1995) 1-25.

[43] Raju S., Chanzy A., Wigneron J.-P., Calvet J.-C., Kerr Y., Laguerre L., Soil moisture and temperature profile effects on microwave emission at low frequencies, Remote Sens. Environ. 54 (1995) 85-97.

[44] Ruf S., Swift C.T., Tanner A.B., Le Vine D.M., Interferometric synthetic aperture microwave radiometry for remote sensing of the earth, IEEE Trans. Geosci. Remote Sens. 26 (1988) 598-612.

[45] Schmugge T., Jackson T.J., Mapping soil moisture with microwave radiometers, Meteorol. Atmos. Phys. 54 (1994) 213-223.

[46] Schmugge T.J., Gloersen P., Wilheit T.T., Geiger F., Remote sensing of soil moisture with microwave radiometers, J. Geophys. Res. 79 (1974) 317-323.

[47] Sellers P.J. et al., Effect of spatial variability in topography, vegetation cover and soil moisture on areaaveraged fluxes, a case study using the FIFE 1989 data, J. Geophys. Res. 100 (1995) 25607 - 25629.

[48] Teng W.L., Wang J.R., Doraiswamy P.C., Relationship between satellite microwave radiometric data, antecedent precipitation index, and regional soil moisture, Int. J. Remote Sensing, 14 (1993) 2483-2500.

[49] Ulaby F.T., Moore R.K., Fung A.K., Microwave Remote Sensing - Active and Passive, vol. 3., Artech House, Norwood, 1986.

[50] van de Griend A.A., Owe M., de Ruiter J., Gouweleeuw B.T., Measurement and behavior of dualpolarization vegetation optical depth and single scattering albedo at $1.4-$ and $5-\mathrm{GHz}$ microwave frequencies, IEEE Trans. Geosci. Remote Sens. 34 (1996) 957-965.

[51] Wang J.R., Microwave emission from smooth bare fields and soil moisture sampling depth, IEEE Trans. Geosci. Remote Sens. 25 (1987) 616-622.

[52] Wang J.R., Choudhury B.J., Remote sensing of soil moisture content over bare field at $1.4 \mathrm{GHz}$ frequency, J. Geophys. Res. 86 (1981) 5277-5282.

[53] Wang J.R., Schmugge T.J., An empirical model for the complex dielectric permittivity of soils as a function of water content, IEEE Trans. Geosci. Remote Sens. 18 (1980) 288-295. 
[54] Wang J.R., O'Neill P.E., Jackson T.J., Engman E.T., Multifrequency measurements of the effects of soil moisture, soil texture, and surface roughness, IEEE Trans. Geosci. Remote Sens 21 (1983) 44-51.

[55] Wang J.R., Shiue J.C., Schmugge T.J., Engman E.T., The L-band PBMR measurements of surface soil moisture in FIFE, IEEE Trans. Geosci. Remote Sens. 28 (1990) 906-913.

[56] Wigneron J.-P., Calvet J.-C., Kerr Y.H., Chanzy A., Lopes A., Microwave emission of vegetation: sensitivity to leaf characteristics, IEEE Trans. Geosc. Remote Sens. 31 (1993) 716-726.

[57] Wigneron J.-P., Chanzy A., Calvet J.-C., Bruguier N., A simple algorithm to retrieve soil moisture and vegetation biomass using passive microwave measurements over crop fields, Remote Sens. Environ. 51 (1995) 331-341.

[58] Wigneron J.-P., Calvet J.-C., Kerr Y., Monitoring water interception by crop fields from passive microwave observations, Agric. Forest Meteorol. 80 (1996) 177-194.

[59] Wigneron J.-P., Combal B., Wegmüller U., Mätzler M., Estimation of microwave parameters of crops from radiometric measurements, Int. J. Rem. Sens. 14 (1996) 2875-2880.

[60] Wigneron J.-P., Guyon D., Calvet J.-C., Courrier G., Bruguier N., Monitoring coniferous forest characteristics using a multi-frequency $(5-90 \mathrm{GHz})$ microwave radiometer, Remote Sens. Environ 60 (1997) 299-310.

[61] Wigneron J.-P., Ferrazzoli P., Calvet J.-C., Kerr Y., Bertuzzi P., Optimal configurations of microwave remote sensing sensors to monitor soil and vegetation A model analysis, IEEE Trans. Geosci. Remote Sens., submitted. (1998)

[62] Wilheit T., Radiative transfer in a plane stratified dielectric, IEEE Trans. Geosci. Electron. 16 (1978) 134-143.

[63] Wood E.F., Lin D.-S., Troch P.A., Mancini M., Jackson T.J., Soil moisture estimation: comparisons between hydrologic model estimates and remotely sensed estimates, in: Choudhury B.J., Kerr Y., Njoku E., Pampaloni P. (Eds.), Passive microwave remote sensing of land-atmosphere interactions, ESA/NASA International Workshop 1993 (St Lary), VSP, Utrecht, 1995, pp. 77-92. 